\title{
Erosion Hazards and Efficient Preservation Measures in Prehistoric Cultural Layers in the Littoral of Lake Constance (Germany, Switzerland)
}

\author{
Wolfgang Ostendorp,Frank Peeters and Hilmar \\ HOFMANN \\ Limnologisches Institut der Universität Konstanz, Konstanz \\ HeLMut SCHLichtherLe
}

Landesamt für Denkmalpflege (LAD) im Regierungspräsidium Stuttgart Gaienhofen-Hemmenhofen, Germany

HANSJÖRG BREM

Amt für Archäologie des Kantons Thurgau, Frauenfeld, Switzerland

\begin{abstract}
Many Neolithic and Bronze Age cultural layers and pile fields embedded in sediments at the shorelines of pre-alpine lakes in France, Switzerland, Germany, Austria, and Italy (in part UNESCO World Heritage Sites), are threatened by littoral erosion which is partly caused by human agency. Based on measurements of the wave field at four prehistoric sites on Lake Constance (Germany, Switzerland) we discuss the role of passenger ship navigation. We also review the stability and ecological compatibility of archaeological preservation control fills on the littoral platform of Lake Constance, and we make some recommendations for future preservation measures.
\end{abstract}

KEYWORDS erosion markers, monitoring, sediments, UNESCO World Heritage, pile dwellings, waves, currents.

\section{Introduction}

The peri-alpine lake dwellings of the Neolithic and Bronze Age form the most prominent cluster of prehistoric wetland sites in Europe. From a total of 937 known sites, I I w were 


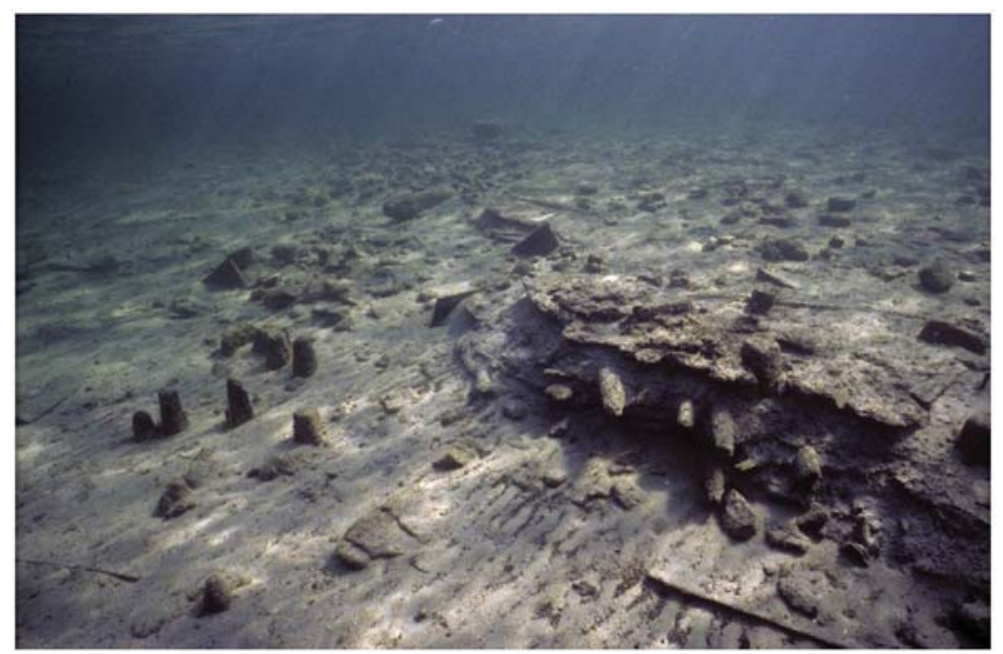

FIGURE 1 Erosion at the prehistoric lake dwelling site of Sipplingen was triggered by retaining walls and harbour construction which have seriously affected cultural layers and wooden structures. Today the process has been slowed down by various preventive measures. Photograph by LAD /M. Kinsky, Freiburg

collectively added to the list of United Nations Educational, Scientific and Cultural Organization (UNESCO) World Heritage Sites in 20II as the serial site 'Prehistoric Pile Dwellings around the Alps' (UNESCO, 20II; http://whc.unesco.org/en/list/I363; Köninger \& Schlichtherle, 20I6: Figure I). Ninety-two of these sites are situated at the edge of thirty-seven peri-alpine lakes between $0.0 \mathrm{I}$ and $580 \mathrm{~km}^{2}$ in size. Out of these ninety-two, seventy-six are potentially affected by waves, littoral currents, sediment erosion, and nearshore human activity.

At Lake Constance, ten out of over ninety lake shore sites are World Heritage Sites, and all but one have been eroded (Figure I). The cultural remains have been dated by dendrochronology from the Late Neolithic (3919 BC) to the Late Bronze Age (843 BC). In this paper we outline the potential impact of waves and currents, sediment transport, passenger ship navigation, and shoreline reinforcement on the World Heritage Sites in the western part of Lake Constance (Germany, Switzerland). We also examine the constructional stability and ecological compatibility of erosion control measures which were especially designed for the preservation of underwater monuments.

\section{Investigation site: Lake Constance}

Lake Constance is a large $\left(529 \mathrm{~km}^{2}\right)$ and deep (max. depth $253 \mathrm{~m}$ ) lake in the northern Alpine foothills. It is subdivided into the large Obersee, the canyon-like Überlingersee, and the Untersee which is the shallowest part towards the outflow. The shoreline is densely settled with many private estates bordering the shoreline, and with well-developed recreational facilities. Thirty out of sixty-eight prehistoric sites along the German shore are situated on intensely used sections, often in front of the retaining walls of private estates, close to harbours and dredged navigation routes, and exposed to the wash from 
ships. Most of the results reported in this paper are derived from studies at the prehistoric sites Sipplingen-Osthafen (Site code SIPP, $47.793^{\circ} \mathrm{N}$ 9.10 $3^{\circ} \mathrm{E}$ ), UnteruhldingenStollenwiesen (UUHL, $47.721^{\circ} \mathrm{N} 9.228^{\circ} \mathrm{E}$ ), Litzelstetten-Krähenhorn (KRAH, $47.724^{\circ}$ $\mathrm{N}$ 9.179 ${ }^{\circ} \mathrm{E}$ ) on the German shore, and Ermatingen-Westerfeld (ERMW, $47.673^{\circ} \mathrm{N} 9.072^{\circ}$ E) and Steckborn-Schanz (STEC, $47.669^{\circ} \mathrm{N} 8.986^{\circ} \mathrm{E}$ ) in the Swiss Canton of Thurgau (see Figure 6).

When the first archaeological survey in the littoral zone of Lake Constance began in the I970s it became evident that many prehistoric sites were exposed to surface erosion and degradation (Bürgi \& Schlichtherle, I986). Meanwhile, the authorities of the Federal State of Baden-Württemberg and the Canton of Thurgau carried out thirteen in situ preservation projects of various types, for example, extensive gravel fills with and without underlying geo-textile, plastic fabric, and coconut fibre mats, sack-like fabric filled with stones at the foot of eroded embankments, and sheet piles (Köninger \& Schlichtherle, 2013, 20I6; Brem \& Schnyder, 20I3, and the literature cited therein).

\section{Methods}

Evidence of recent erosion to the monuments was observed by divers during archaeological surveys and test excavations. The work started in I980, and was intensified over the years, and will be continued in the foreseeable future. To investigate medium-term erosion/accretion rates, we tested several kinds of markers (Mainberger \& Hohl, 20I3). Wooden poles of $0.04 \times 0.04 \times \mathrm{I} .5 \mathrm{~m}$ were driven into the littoral floor to a defined height above the recent sediment surface. A total of 245 markers have been exposed and are ready for monitoring (Figure 2).

The characteristics of the surface wave field and the resuspension of particles in the shallow water zone were measured continuously between 2008 and 20II (Hofmann, et al., 20I3). All relevant wave parameters (wave height, period, length, wave energy, and energy flux) were calculated for I-min intervals from pressure sensors, and thereafter analysed statistically (Hofmann, et al., 2008). Further properties such as the maximum resuspendable grain size were determined by empirical relations based on the properties of the wave field.

The surface wave field of Lake Constance was simulated with the wave model SWAN (Simulating Waves Nearshore) at a high spatial and temporal resolution over long time periods (Seibt, et al., 20I3; Hofmann, et al., 2013). The aim of the model simulations was to determine, in addition to the wave field, the wave exposure and resuspension potential of the shores around Lake Constance. The significant wave height $\left(\mathrm{H}_{\text {sig }}\right)$ and the maximum near-bottom current velocity $\left(\mathrm{u}_{\max }\right)$ were used as a measure of the wave exposure of the shores.

Archaeological protection against littoral sheet erosion consisted of large gravel fills 0.2 to $0.3 \mathrm{~m}$ in thickness which buried the original fine sediment surface, the vulnerable cultural layers, and the bases of prehistoric piles (Königer \& Schlichtherle, 20I6). The bulk material was a mixture of $8-\mathrm{I} 6 \mathrm{~mm}$ pebbles and $32-\mathrm{I00} \mathrm{mm}$ cobbles $(\mathrm{I}+2$ parts $\mathrm{m} / \mathrm{m}$ ). The fills were applied in autumn I998 (ERMW, only the grain size $8-16 \mathrm{~mm}$ ), in 2009 (KRAH, SIPP), and in $201 \mathrm{II}$ (STEC).

The pre-examination of KRAH, SIPP and STEC was performed in July and August 2008 , and the follow-up investigations were carried out in 2010 (KRAH, SIPP) and 2012 


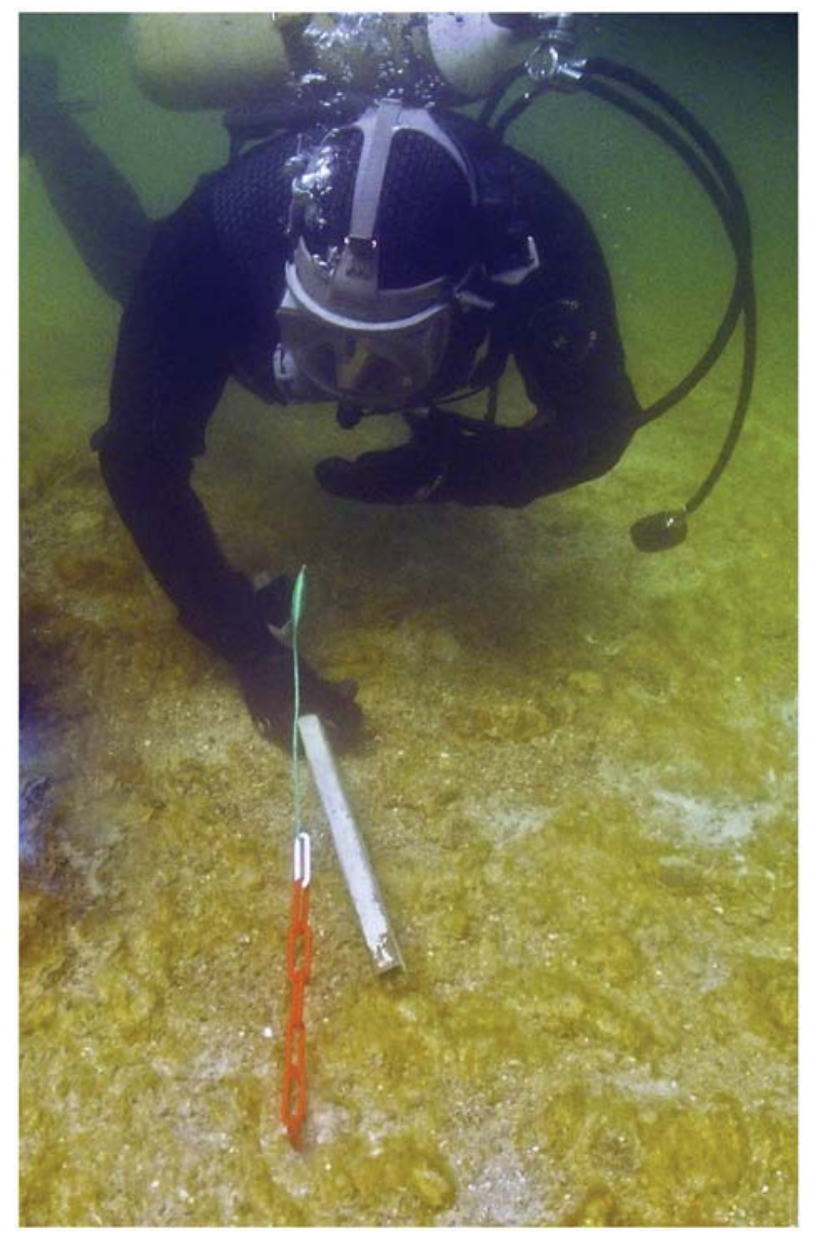

FIGURE 2 Scientific diver controlling erosion markers, in this case in form of a plastic chain. Photograph by LAD /M. Mainberger, UWARC, Staufen

(STEC), applying the same protocol (Figure 3). The site ERMW, investigated in 20I0, represents a preservation measure after twelve years of development (Figure 4). The investigation scheme included the stability of the fills, and analysis of surface sediments, submerged vegetation, invertebrates, and fish.

\section{Results}

\section{Surface wave field: wind waves and ship-induced waves}

The surface wave field of Lake Constance is characterized by wind waves as well as waves caused by the wash from ships. The waves generated by ferries and passenger ships can significantly contribute to the overall wave energy dissipated in the lake shore, and thus form a potential vector for the resuspension of nearshore sediments (Hofmann, et al., 2008, 20II; Hofmann, et al., 20I3). Ship waves can reach heights of $0.05-0.3 \mathrm{~m}$ and last 


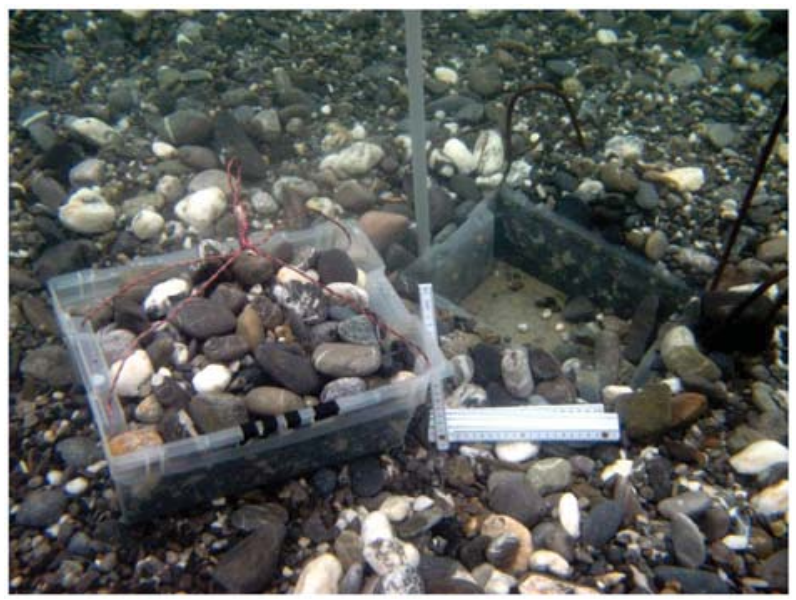

FIGURE 3 Experimental container on the top of the fill in the site Litzelstetten-Krähenhorn (KRAH), November 2009, before inserting it into a nestable container of the same size (behind right). The container had been filled with the same bulk material and served for invertebrate sampling and for colmatation experiments.

Photograph by J. Köninger, terramare Freiburg i. Br., Germany

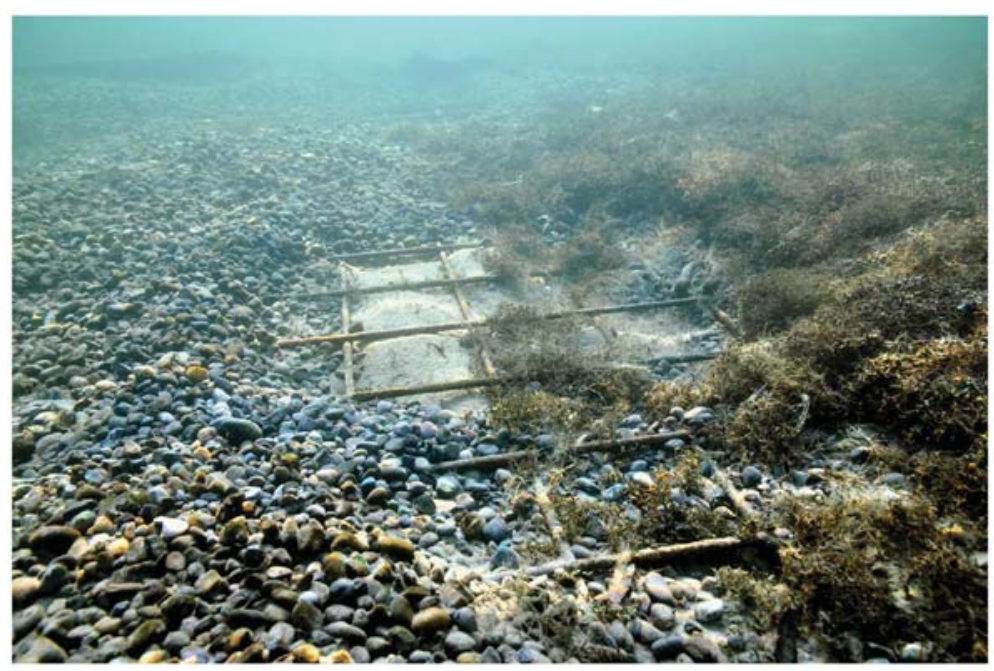

FIGURE 4 Gravel fill at the site Ermatingen-Westerfeld (ERMW) with underlying geo-texile fixed on a reinforcement mat. The exposed geo-texile is the result of grazing activities of mute swans and anchoring of boats.

Photograph by M. Schnyder, Cantonal Archaeology Department of Thurgau

for $3-4$ s. In contrast, the wave heights and duration of wind-generated waves at the studied sites amount to $0-0.8 \mathrm{~m}$ and $\mathrm{I}-2.5 \mathrm{~s}$. 

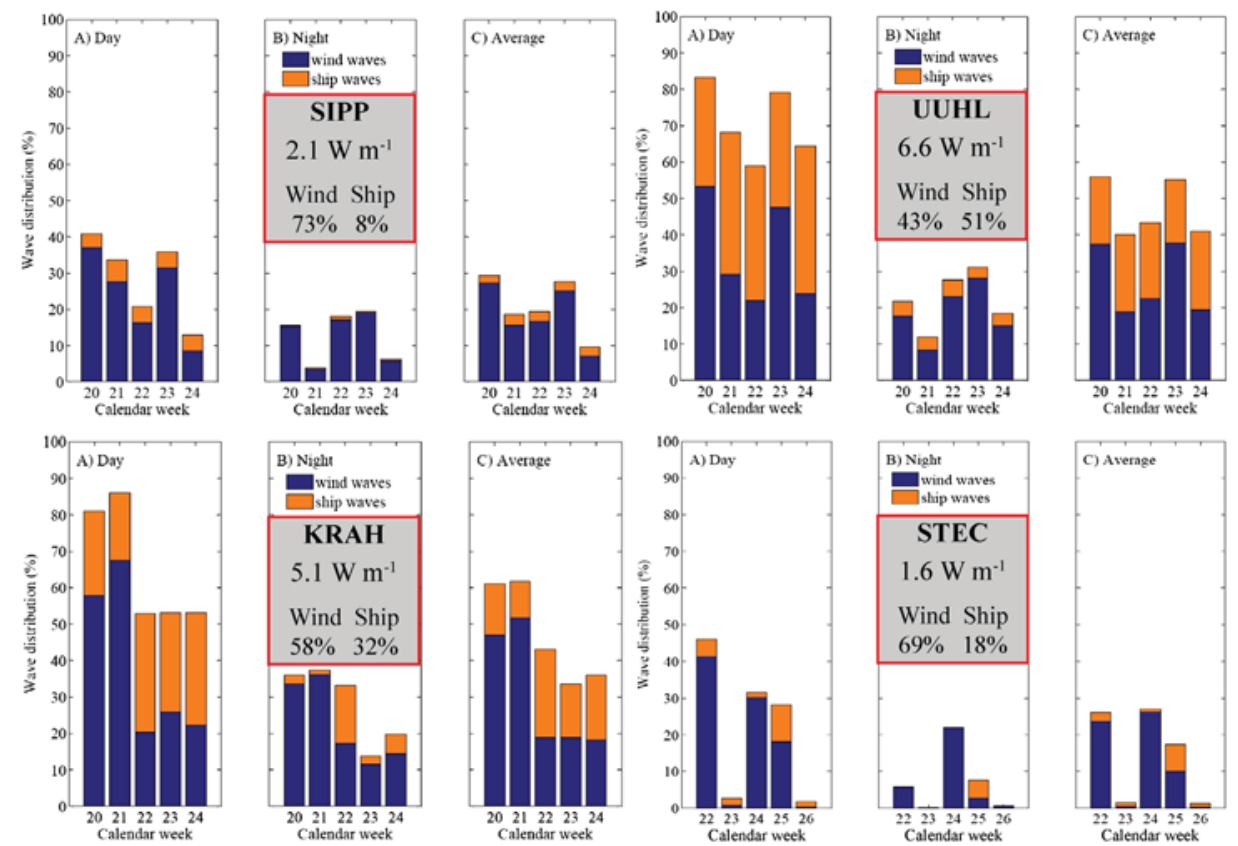

FIGURE 5 Wave statistics: relative frequency (\%) of wind and ship waves. (A) day (09-21 hh), (B) night (21-09 hh) and (C) daily average at the sites SIPP, UUHL, KRAH, and STEC. Wave heights below $0.05 \mathrm{~m}$ were excluded from the data sets and are expressed by the missing percentage to $100 \%$.

The statistical analysis of the wave data time series at SIPP, UUHL, KRAH, and STEC calculated the different exposure of the study sites to wind and ship waves, for example, during summer (Figure 5). During the day, more waves reach the shore than at night, caused by the presence of ships. At the sites UUHL and KRAH, most of the waves reaching the shore stem from ships, which can be explained by the harbour nearby (UUHL) and the adjacent navigation route (KRAH).

Ship waves can dominate the energy in the wave field during the day and can contribute up to $50 \%$ of the wave energy dissipated at the lake shore (wave energy flux) during summer (e.g. in UUHL; Figure 5, Table I). In winter, most of the wave energy flux to shore stems from wind (Table I). At that time, the wave energy flux to shore is dominated by single, short-lasting but intense energy wind events. This is in contrast to the situation during summer, where ship waves contribute a much less intensive but steady flux of wave energy to the lake shores.

The long-term average (2008-II) wave exposure in terms of absolute wave energy flux to shore and the relative contribution of wind and ship waves at UUHL, KRAH, STEC and SIPP are presented in Table I. On average, the different sites can by ordered according to their wave exposure as follows: UUHL $>$ KRAH $>$ STEC $>$ SIPP.

Using the wave model SWAN we found that the sites SIPP, UUHL, KRAH, and STEC show at $\mathrm{I}-2,5-6,3-4$ and $2-3 \%$ of the time of the year waves with a height of $0.15 \mathrm{~m}$ and more (Figure 6). Wave heights of greater than 0.15 $\mathrm{m}$ are expected to cause resuspension 
Table 1

WAVE STATISTICS: LONG-TERM (2008-11) AVERAGE WAVE EXPOSURE OF THE STUDY SITES SIPP, UUHL, KRAH, AND STEC IN TERMS OF WAVE ENERGY FLUX TO SHORE AND THE RELATIVE CONTRIBUTION OF WIND WAVES (WW) AND SHIP WAVES (SW).

\begin{tabular}{|c|c|c|c|c|c|c|}
\hline \multirow[b]{2}{*}{ Site } & \multicolumn{3}{|c|}{ Energy flux to shore - Summer } & \multicolumn{3}{|c|}{ Energy flux to shore - Winter } \\
\hline & Abs. $a v\left(\mathrm{~W} \mathrm{~m}^{-1}\right)$ & WW \% & SW \% & Abs. av $\left(\mathrm{W} \mathrm{m}^{-1}\right)$ & WW \% & SW \% \\
\hline SIPP & 3 & 85 & 15 & 2 & 96 & 4 \\
\hline$U U H L$ & 8 & 56 & 44 & 8 & 98 & 2 \\
\hline$K R A H$ & 5 & 65 & 35 & 3 & 87 & 13 \\
\hline STEC & 2 & 77 & 23 & 4 & 98 & 2 \\
\hline
\end{tabular}

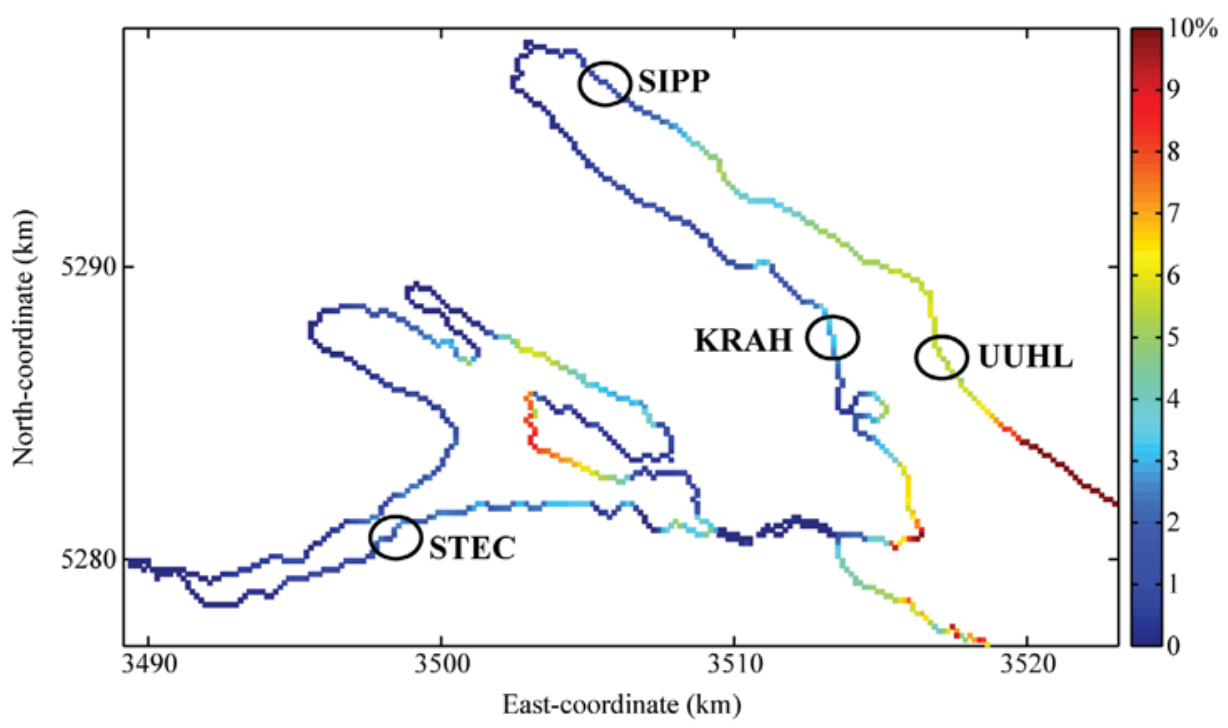

FIGURE 6 Spatially resolved mean wave exposure of the shores in Lake Constance/Überlingersee and Untersee (incl. the sites SIPP, UUHL, KRAH, and STEC) between February 2009 and January 2010. The colour coding indicates the fraction of $1 \mathrm{~h}$ time intervals of the overall simulations period during which the wave heights exceeded $0.15 \mathrm{~m}$.

of particles in the shallow water zone. UUHL has the highest wave exposure of all investigated sites, which corresponds to the longest effective wind fetch of all sites and its exposure to westerly winds (i.e. the dominant wind direction on Lake Constance). In contrast, the site SIPP showed the lowest wave exposure due to the shorter effective fetch. The wave exposures of KRAH and STEC, which are exposed to north-easterly winds, are in between. In this manner, the model simulations allow lake-wide prediction of the wave effect on shores around Lake Constance.

Furthermore, the data of the surface wave field model can be used to predict the resuspension potential of particles in the shallow water zone. Therefore, timed step-modelled wave parameters were combined with the spatial distribution of the fine-grained sediment 
fraction using empirical relations (CERC, I984). Together this allows the assessment of the temporal and spatial distribution of sediment resuspension.

\section{Preservation measures: stability, ecological consequences}

The pre/post and test/reference monitoring of the erosion control fills showed that within one year of deployment, the fills in SIPP, KRAH, and STEC were stable (Ostendorp, et al., 20I3). In some cases a weak vertical separation was visible as the cobbles were concentrated in the uppermost layer, forming a pavement, and the smaller grains were concentrated in the deeper layer. In ERMW, where uniform grains of 8-16 mm had been applied in 1998 , the fills did not consolidate and seemed to be abundantly disturbed, mainly due to the grazing activities of mute swans, Cygnus olor (Figure 4).

A significant infilling of the pore space of the bulk (colmatation) was not observed in the first year (Ostendorp, 20I3). The accretion rate due to fine calcareous and organic matter sedimentation was calculated to be $2.8 \mathrm{~mm}$ (SIPP) and $\mathrm{I} .7 \mathrm{~mm}$ (KRAH) within nine months. Therefore it will be many years before the pore space is completely filled with fine material.

The lack of fine matter influenced the underwater vegetation: after one year the macrophytes (mainly stoneworts, Chara div. spp.) had not been able to recolonize the gravel. The mean coverage was ० $\%$ compared with $22 \%$ (KRAH) and $60 \%$ (SIPP) of the reference sites (Ostendorp, et al., 20I3). However, in the central part of the grid-like fills in SIPP the coverage increased to $80 \%$. In ERMW the submerged vegetation was concentrated on the less disturbed spots (mean coverage 19\%; see Figure 4). It is worth mentioning that the photosynthetic carbonate precipitation of stoneworts amounted to about $0.2 \mathrm{~kg} /$ $\mathrm{m}^{2} / \mathrm{yr}$, and is therefore an important source of sediment matter.

The total density of invertebrates on and in the gravel bed ( $0-35 \mathrm{~mm}$ thickness) was up to $55 \%$ (SIPP) and $78 \%(\mathrm{KRAH})$ of the reference value (100\%: $27,040 \mathrm{ind} . / \mathrm{m}^{2}$ in $\mathrm{KRAH}, 45,457$ ind. $/ \mathrm{m}^{2}$ in SIPP; Ostendorp, et al., 20I3). This was mainly because the vegetation failed on the fills. In the centre of the grid-like fills, the macroinvertebrates seemed to profit from the new situation. Here, $\mathrm{I} 47 \%$ of the total density in the reference site was attained.

Regarding fish, the fills were too small to reveal statistically significant results. We hypothesise that, with the exception of tench (Tinca tinca) and young perch (Perca fluviatilis), many species may potentially profit from the coarse substratum which offers a more diverse habitat than uniform stonewort meadows. In particular, this is thought to be the case for stone loach (Barbatula barbatula) and the bullhead (Cottus cobio; protected species under the European Habitats Directive 92/43/EEC, App. II, Code II63).

Two of the fills on the experimental sites (ERMW, STEC) were supported by underlying geo-textile fixed on reinforcement mats. We assume that geo-textile $0.2 \mathrm{~mm}$ below the top of the gravel fill has no influence on the biota on or just below the substrate surface.

\section{Discussion}

Erosion leading to beach scarps and sheet denudation on the littoral platform seems to be a widespread phenomenon in pre-alpine lakes. An evaluation of the UNESCO nomination documents (UNESCO, 20IO/II) showed that in small lakes ( $\mathrm{A}<\mathrm{Io} \mathrm{km}^{2}$ ) 


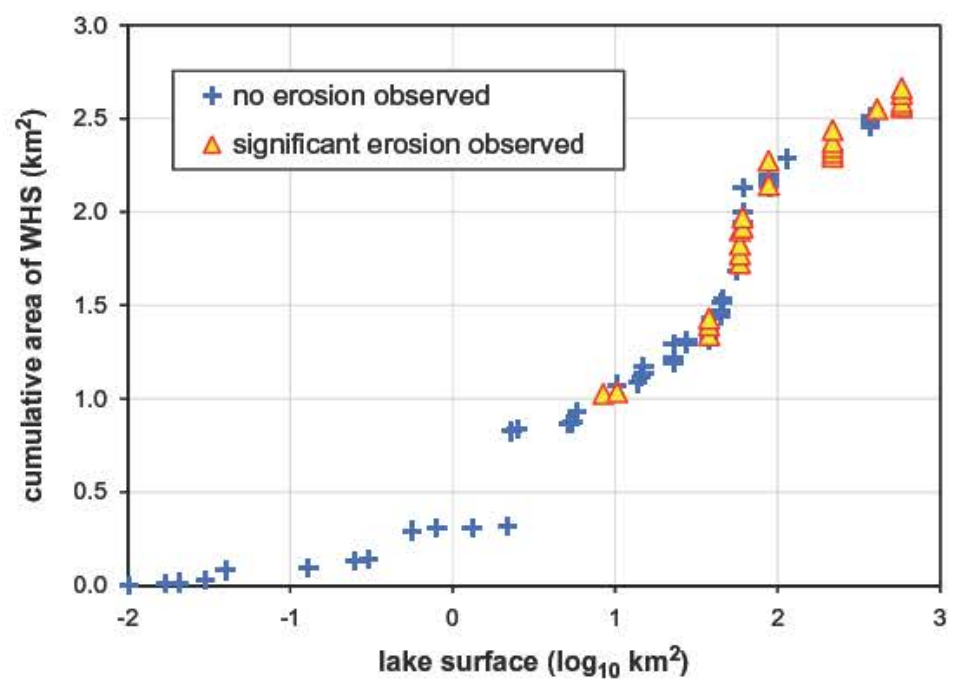

FIGURE 7 Cumulative area of seventy-six UNESCO World Heritage sites on the shores of peri-alpine lakes against the ranked lake surface $\left(\log _{10}\left[A / A_{0}\right], A_{0}=1 \mathrm{~km}^{2}\right)$. Triangles indicate prehistoric sites where significant erosion has been observed. Data extracted from UNESCO (2010/11)

significant erosion has rarely been observed, whereas in large lakes $\left(A=10-580 \mathrm{~km}^{2}\right)$ $40 \%$ of all sites are affected (Figure 7 ). The large lakes are those where passenger ships operate. In lakes without passenger ships none of the seventeen World Heritage Sites were threatened by erosion, whereas in lakes with navigation routes, $4 \mathrm{I} \%$ of sites showed alarming signs of erosion (Figure 8).

In Lake Constance we identified, apart from wind-generated waves, ship-generated waves as a significant source of the wave energy flux to shore at several prehistoric sites. At some of the sites, ship waves dominate the wave field and energy flux to shore during daytime and in summer season.

Urbanism and tourist facilities in the littoral zone are often protected by conventional 'hard' hydraulic-engineering constructions which have the potential to modify the wave climate, and hence modify the sediment budget leading to erosion. Thankfully, in and around most WHS no such structures are found (Figure 9), but in about Io\% of all sites, shore reinforcements and retaining walls (UV, UM), landfills (UA) or bathing jetties and landing stages (BS, ST) are of 'significant' or 'high' importance. $63 \%$ of all sites are completely unspoilt and in $25 \%$ there are multiple structures of two or more types.

This type of human impact, and so-called restoration works (i.e. sloping the existing retaining wall by a wedge-shaped fill with coarse gravel in front of it) will be examined in the recent research project, HyMoBioStrategy (20I5-I8), funded by the German Federal Ministry of Education and Research (grant: 033 Wo2I). The main focus is understanding the interactions between hydrodynamic, hydromorphological, and biotic processes, and on making recommendations for achieving sustainable shoreline management including 


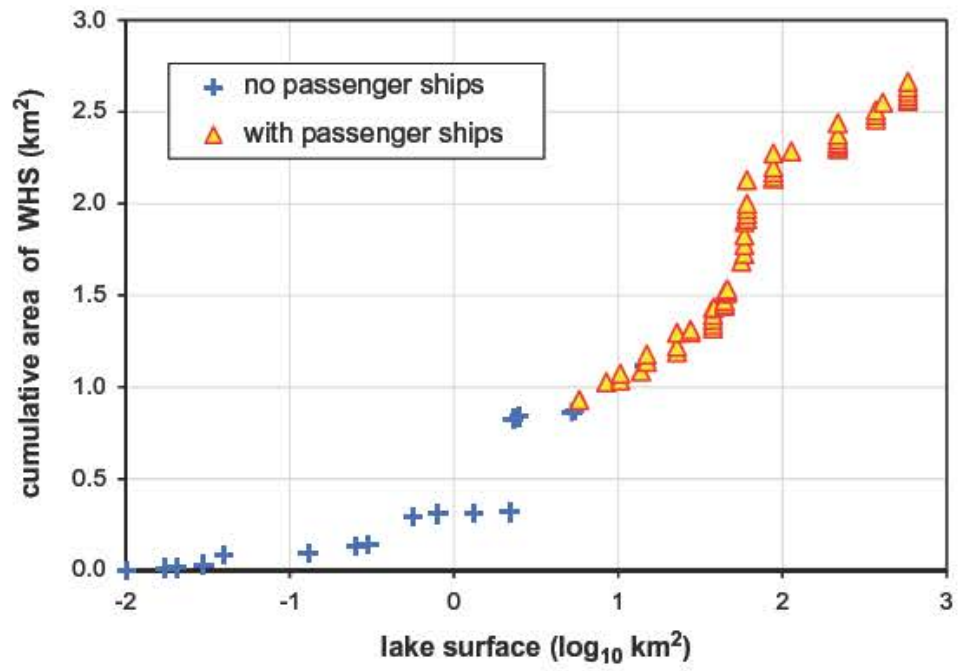

FIGURE 8 Cumulative area of seventy-six UNESCO World Heritage sites on the shores of circumalpine lakes against the ranked lake surface $\left(\log _{10}\left[A / A_{0}\right], A_{0}=1 \mathrm{~km}^{2}\right)$. Triangles indicate prehistoric sites in lakes with abundant passenger ship navigation. Data extracted from UNESCO (2010/2011). http://sites.palafittes.org.

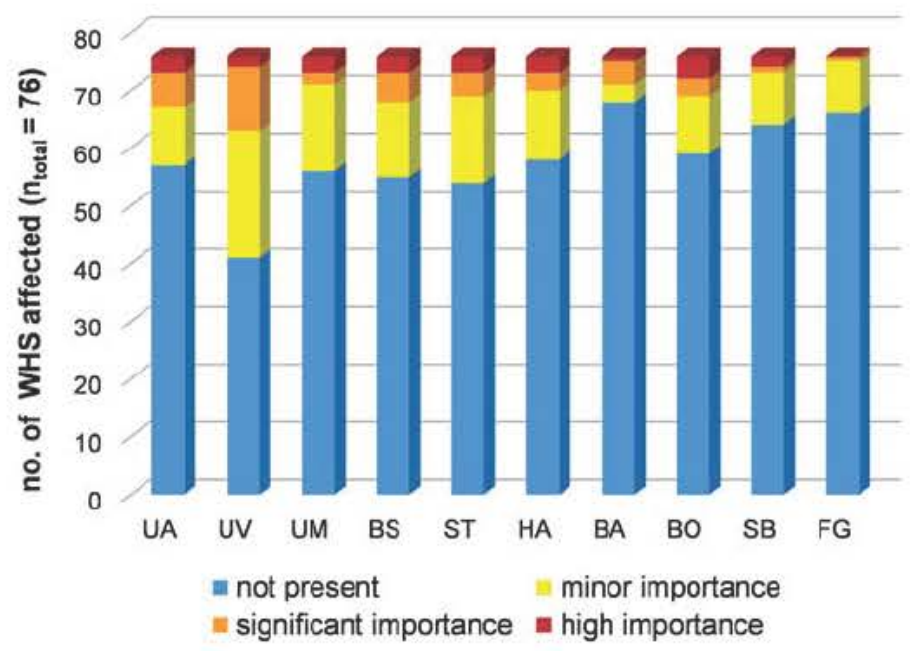

FIGURE 9 Percentage of prehistoric sites which are affected by one out of ten human structure types within the site ('high importance'), next to the site ('significant importance') or some distance from the site ('minor importance'). Data obtained from the maps of the UNESCO nomination documents (UNESCO, 2010/11) and from recent aerial photographs. UA - landfills, UV - shore reinforcements, UM - retaining walls, BS - bathing jetties, ST - (small) landing stages, HA - harbours (with piers), BA - underwater dredging, BO - moored buoy fields, SB - bathing beaches, FG - (large) boarding bridge. 
restoration strategies with regard to the existing, intensive demands (recreation, tourism) and conflicts of sustainability (Natura 2000 network, UNESCO World Heritage Sites).

Even in untouched littoral sectors, erosion can be caused by foraging by waterfowl, native fish species like eel (Anguilla anguilla) and invasive crayfish species (e.g. American crayfish, Orconectes limosus), as observed in Lake Constance.

Though the elementary processes during solid matter resuspension and transport by waves and currents are well known from marine environments (Dyer, I986; Brown, et al., 2005) and some large lakes (e.g. Lake Michigan, Lake Erie, Lake Constance; Hawley \& Lee, I999; Luettich, et al., I990; Hofmann, et al., 20II), the reasons and circumstances are not.

Regardless of many persistent research gaps, in the I980s the State Office for the Preservation of Historical Monuments Baden-Württemberg (Germany) and the Cantonal Archaeology Department of Thurgau (Switzerland) started underwater preservation measures in Lake Constance. Generally, the preservation works were stable and effective. However, in ERMW the grain size $(8-16 \mathrm{~mm}$ diameter) was too small. Bedload transport experiments with artificial tracers confirmed this finding: grain sizes of $35.5-63 \mathrm{~mm}$ and 63-200 mm did not move more than 0.5-I.5 $\mathrm{m}$ in two years (Ostendorp \& Härter, 20I3).

Along the German shore of Lake Constance many endangered archaeological sites are located in protected areas (Natura 2000 network areas under the European Habitats Directive, I992, state nature reserves). Therefore, preservation needs to be undertaken carefully in order to minimize any permanent impact on ecology. The strongest impact was the coarsening of the substrate surface combined with a negligible infilling of fine sediment, leading to a nearly complete absence of stoneworts, which in turn impacted invertebrates adversely, although this did not affect the fish. We recommend the following measures to minimize ecological harm:

I. using a wide range of grain sizes instead of a homogenous bulk material. The largest cobbles of about $63-200 \mathrm{~mm}$ should ensure that swans cannot pick them up. In addition to pebbles of $c .35 .5-63 \mathrm{~mm}$ (which have been used to date), high proportions of medium-sized gravel $(6.3-20 \mathrm{~mm})$ should also be used in order to quickly fill up the pore space;

2. using grid-like fill areas, instead of extensive homogenous fills, wherever possible. This would reduce costs and offers the opportunity for later test sondages or other kinds of monitoring of the cultural layers. A monitoring scheme should verify that accretion is occurring in the interior;

3. placing boulders $(>250 \mathrm{~mm})$ onto the bed to enhance conditions for bottom dwelling fish species.

In addition, buoy fields in archaeological sites should be removed (see UNESCO, 2OII: 227), since the swinging circles, caused by the anchor chains of the boats, not only destroy the submerged vegetation (Ostendorp, et al., 2008) but also scrape the near-surface cultural layers and generate frequent resuspension of the sediment. Essentially the same applies to the occasional anchoring of boats in those sites. Furthermore, other measures to locally reduce the wave energy flux to shore should be considered, for example, reduction of the speed of passenger ships especially during the docking and departure manoeuvres, more distant navigation routes, and mitigation of the shore reinforcements and retaining walls. 
Finally, we recommend periodic monitoring to check the preservation of the cultural layers and the ecological development of the fill area.

\section{Acknowledgements}

Parts of this work were supported by the German Research Foundation (DFG) within the framework of the Collaborative Research Center 454 'Littoral Zone of Lake Constance' and by the European Regional Development Fund (ERDF) within the framework of the European Territorial Cooperation (INTERREG IV) 'Erosion und Denkmalschutz am Bodensee und Zürichsee.' We also wish to thank Jamie McIntosh for linguistic improvements.

\section{Bibliography}

Brem, H. \& Schnyder, M. 20I3. Schutzmassnahmen für Pfahlbausiedlungen am Thurgauer Bodenseeufer. In: H. Brem, B. Eberschweiler, G. Grabher, H. Schlichtherle and H.G. Schröder, eds. Erosion und Denkmalschutz am Bodensee und Zürichsee. Bregenz: Vorarlberg Museum, pp. I27-I29.

Brown, E., Colling, A., Park, D., Phillips J., Rothery, J.D. \& Wright, J. 2005. Waves, Tides and Shallow-Water Processes. 2nd ed. Boston: Butterworth-Heinemann.

Bürgi, J. \& Schlichtherle H. 1986. Gefährdete Ufersiedlungen am Bodensee. Archäologie Schweiz, 9: 34-4I.

CERC. 1984. Shore protection manual. Volume. I. Vicksburg, Mississippi, US Army Coastal Engineering Research Center (Books for Business).

Dyer, K.R. I986. Coastal and Estuarine Sediment Dynamics. Chichester: John Wiley.

European Habitats Directive. I992. Council Directive 92/43/EEC of 21 May I992 on the conservation of natural habitats and of wild fauna and flora. Official Journal of the European Communities, 35: L 206/7-206/50.

Hawley, N. \& Lee, C.H. I999. Sediment resuspension and transport in Lake Michigan during the unstratified period. Sedimentology, 46: 79I-805.

Hofmann, H., Lorke, A. \& Peeters, F. 2008. The relative importance of wind and ship waves in the littoral zone of a large lake. Limnology and Oceanography, 53 (I): 368-380.

Hofmann, H., Lorke, A. \& Peeters, F. 20II. Wind and ship wave-induced resuspension in the littoral zone of a large lake. Water Resources Research, 47 (9). doi:I0.I029/20IoWRoIooI2.

Hofmann, H., Seibt, C. \& Peeters, F. 2013. Wellenexposition und Resuspensionspotential ausgewählter Untersuchungsgebiete am Bodensee: Messungen und Modellierung. In: H. Brem, B. Eberschweiler, G. Grabher, H. Schlichtherle and H.G. Schröder, eds. Erosion und Denkmalschutz am Bodensee und Zürichsee. Bregenz: Vorarlberg Museum, pp. 37-5I.

Köninger, J. \& Schlichtherle, H. 20I3. Schutzmassnahmen für Pfahlbausiedlungen am baden-württembergischen Bodenseeufer. Verfahrenstechniken, Bestand, Erfahrungen und Ausblick. In: H. Brem, B. Eberschweiler, G. Grabher, H. Schlichtherle and H.G. Schröder, eds. Erosion und Denkmalschutz am Bodensee und Zürichsee. Bregenz: Vorarlberg Museum, pp. II3-I26.

Köninger, J. \& Schlichtherle, H. 20I6. Lake dwellings in Baden-Wuerttemberg. Conservation projects in situ at Lake Constance and the Federsee Moor. Conservation and Management of Archaeological Sites, this volume.

Luettich Jr, R.A., Harleman, D.R.F. \& Somlyody, L. I990. Dynamic behavior of suspended sediment concentrations in a shallow lake perturbed by episodic wind events. Limnology and Oceanography, 35 (5): 1050-1067.

Mainberger, M. \& Hohl, W. 2013. Monitoring in archäologischen Denkmalen in der Flachwasserzone. Eine Einführung in Techniken und Methoden. In: H. Brem, B. Eberschweiler, G. Grabher, H. Schlichtherle and H.G. Schröder, eds. Erosion und Denkmalschutz am Bodensee und Zürichsee. Bregenz: Vorarlberg Museum, pp. I83-196.

Ostendorp, W. 20I3. Erosionsinstabile Sedimentfraktionen in den Unterwasserdenkmal-Stationen LitzelstettenKrähenhorn und Sipplingen-Osthafen am Bodensee. In: H. Brem, B. Eberschweiler, G. Grabher, H. Schlichtherle and H.G. Schröder, eds. Erosion und Denkmalschutz am Bodensee und Zürichsee. Bregenz: Vorarlberg Museum, pp. $67-77$.

Ostendorp, W. \& Härter, C.S. 2013. Sohltransport in der Flachwasserzone des Bodensees: Methodenentwicklung und erste Ergebnisse. In: H. Brem, B. Eberschweiler, G. Grabher, H. Schlichtherle and H.G. Schröder, eds. Erosion und Denkmalschutz am Bodensee und Zürichsee. Bregenz: Vorarlberg Museum, pp. 79-93. 
Ostendorp, W., Gretler, T., Mainberger, M., Peintinger, M. \& Schmieder, K. 2008. Effects of mooring management on submerged vegetation, sediments and macro-invertebrates in Lake Constance, Germany. Wetlands Ecology and Management, I7 (5): 525-54I.

Ostendorp, W., Dienst, M., Kramer, I. \& Strang, I. 20I3. Ökologische Begleituntersuchungen an drei denkmalpflegerischen Erosionssicherungsmassnahmen am deutschen und schweizerischen Bodenseeufer. In: $\mathrm{H}$. Brem, B. Eberschweiler, G. Grabher, H. Schlichtherle and H.G. Schröder, eds. Erosion und Denkmalschutz am Bodensee und Zürichsee. Bregenz: Vorarlberg Museum, pp. I49-I70.

Seibt, C., Peeters, F., Graf, M., Sprenger, M. \& Hofmann, H. 2013. Modeling wind waves and wave exposure of nearshore zones in medium-sized lakes. Limnology and Oceanography, 58 (I): 23-36.

UNESCO. 20II. United Nations Educational, Scientific and Cultural Organization 20II: Decisions adopted by

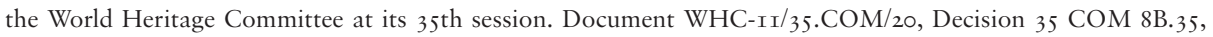
pp. 225-227. Paris, 7 July 201 I.

UNESCO. 20Io/Ir. United Nations Educational, Scientific and Cultural Organization, ed. 20IO, 20II. Prehistoric Pile Dwellings around the Alps - World Heritage nomination. Nomination Dossier: Executive summary (20IO, revised in 20II), Volumes I, II, III (20I0) and Additional Information (20II). Paris. [Accessed July 20I5] Available at: <http://www.palafittes.org/en/products-downloads/news/index.html> 